\title{
BMJ Open A group-based HIV and sexually transmitted infections prevention intervention for lesbian, bisexual, queer and other women who have sex with women in Calgary and Toronto, Canada: study protocol for a non-randomised cohort pilot study
}

Carmen H Logie, ${ }^{1,2}$ Daniela Navia, ${ }^{3}$ Marie-Jolie Rwigema, ${ }^{1}$ Wangari Tharao, ${ }^{4}$ David Este, ${ }^{5}$ Mona R Loutfy ${ }^{2}$

To cite: Logie $\mathrm{CH}$, Navia D, Rwigema M-J, et al. A groupbased HIV and sexually transmitted infections prevention intervention for lesbian, bisexual, queer and other women who have sex with women in Calgary and Toronto, Canada: study protocol for a non-randomised cohort pilot study. BMJ Open 2014:4:e005190. doi:10.1136/ bmjopen-2014-005190

- Prepublication history and additional material for this paper is available online. To view these files please visit the journal online (http://dx.doi.org/10.1136/ bmjopen-2014-005190).

Received 4 March 2014 Accepted 27 March 2014

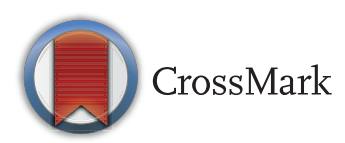

For numbered affiliations see end of article.

Correspondence to Carmen H Logie; carmen.logie@utoronto.ca

\section{ABSTRACT}

Introduction: The limited research that exists suggests that lesbian, bisexual queer (LBQ) and other women who have sex with women are at similar risk for sexually transmitted infections (STI) as heterosexual women. However, scant research has evaluated HIV and STI prevention strategies for LBQ women. The authors present the rationale and study protocol for developing and pilot testing a psychoeducational group-based HIV and STI prevention intervention with $L B Q$ women in Calgary and Toronto, Canada.

Methods and analysis: This is a multicentre nonrandomised cohort pilot study. The target population is LBQ women in Calgary and Toronto, Canada. The authors aim to recruit 40 participants using purposive peer-driven recruitment methods. Participants will conduct a pretest followed by a 2-day group programme of six $2 \mathrm{~h}$ sessions addressing stigma, STI and HIV prevention, healthy relationships, safer sex self-efficacy, self-worth, social support and LBQ community engagement. Participants will conduct a post-test directly following the intervention and 6 weeks after the intervention. The primary outcome is safer sex practices; our prespecified index of clinically significant change is an effect size of 0.50 . Secondary outcomes include: safer sex self-efficacy, STI testing frequency, STI knowledge, resilient coping, social support, sexual stigma, access to care, depression and self-esteem. We will conduct mixed-effects regression to calculate mean outcome pre-post test score change. Ethics and dissemination: Research ethics approval was attained from the Office of Research Ethics (REB: 29291), University of Toronto, Toronto, Ontario, Canada. Trial results will be published according to the Transparent Reporting of Evaluations with Nonrandomised Designs (TREND) statement, regardless of the outcomes.

\section{Strengths and limitations of this study}

- First trial to evaluate a psychoeducational HIV and sexually transmitted infections (STI) prevention intervention among lesbian, bisexual, queer women.

- Intervention design was theoretically informed by the social ecological framework to explore intrapersonal, interpersonal, community and structural drivers of HIV and STI.

- Non-randomised design and the lack of control group could limit external validity.

Trial registration number: This study is registered at http://clinicaltrials.gov, registration number NCT02067845.

\section{INTRODUCTION}

The importance of addressing STI among lesbian, bisexual and queer women

Efficacious strategies for sexually transmitted infections (STI) prevention among lesbian, bisexual and queer (LBQ) women are understudied. ${ }^{1-6}$ While LBQ women are often perceived to be at low risk for STIs, including HIV infection, evidence demonstrates transmission between women of STIs such as trichomoniasis, human papillomavirus, herpes simplex virus and hepatitis B. ${ }^{1}{ }^{3-7}$ While the risk of HIV transmission is plausibly much lower, the issue is rarely examined in this population and is not zero. Researchers have described LBQ women have similar STI 
incidence as heterosexual women. ${ }^{3} 78$ A study conducted with $\mathrm{LBQ}$ women $(\mathrm{n}=440)$ in Toronto, Canada ${ }^{9}$ found that one-fifth of LBQ women reported a history of an STI. These STI rates corroborate STI rates among LBQ women in the USA. ${ }^{1}$ Research in Brazil ${ }^{6}$ and Canada ${ }^{9}$ has highlighted gaps between LBQ women reporting knowledge of safer sex practices yet not implementing safer sex strategies into sexual practices.

While there is a dearth of knowledge regarding social determinants of HIV and STI infections among LBQ women, gender-based violence and sexual stigma have been identified as significant factors that elevate HIV and STI infection risks. ${ }^{9-13}$ Sexual stigma is a social process that involves the devaluation of sexual minorities that results in less power provided to same-sex sexual practices, identities, relationships and communities. ${ }^{14}$ Research among men who have sex with men (MSM) also suggests that maladaptive coping styles, in addition to sexual stigma, may be associated with sexual risk behaviour. ${ }^{15-17}$ This evidence suggests that sexual stigma and coping styles may be salient areas to address in reducing HIV and STI vulnerability among LBQ women.

Of particular concern is lower utilisation of sexual health services among LBQ women. Despite similar rates of STI infection as heterosexual women, LBQ women may not engage in routine gynaecologist appointments ${ }^{6}$ or HIV/STI testing. ${ }^{1}$ In fact, Statistics Canada data indicated that lesbians reported significantly lower rates of Pap testing than heterosexual or bisexual women, lesbians and bisexual women had higher odds of not having a regular doctor than heterosexual women, and bisexual women had higher reported unmet healthcare needs than lesbian and heterosexual women. ${ }^{18}$ No information, however, was collected in this report regarding HIV and STI incidence and testing frequencies among LBQ women.

A history of exclusion of sexual minority women within health services may contribute to low levels of engagement of LBQ women within HIV and STI prevention services. ${ }^{19}{ }^{20} \mathrm{Few}$ services are currently tailored to meet the needs of $\mathrm{LBQ}$ women ${ }^{21}$ and care is often perceived as inadequate. ${ }^{22-24} \mathrm{~A}$ key issue is whether or not individuals feel comfortable disclosing their sexual orientation to their healthcare providers. Lesbian, gay, bisexual and queer (LGBQ) persons often choose to hide their sexual orientation from providers due to concerns about confidentiality, fear of lower standards of care, concerns about the relevance of disclosure and fear of a negative or inappropriate response. ${ }^{25-30}$ Training for healthcare providers to increase their knowledge of LGBQ issues and to tailor services to enhance appropriateness for LGBQ persons are crucial for improving quality of care. ${ }^{31} 32$ Additionally, since interventions and programmes often presume that LGBQ people are part of a homogeneous community and often presumed to be white, male and able-bodied, an emphasis on working specifically with LBQ women and other minority groups is needed..$^{33} 34$

Behavioural interventions that address social and structural drivers of HIV and STI vulnerability among LBQ women are seldom implemented or validated. Behavioural interventions may involve individual counselling, social and/or behavioural support, including peer education and exploration of values, beliefs, motivation, attitudes, structural barriers and meanings of sexuality. ${ }^{35}$ There is only one published study detailing the development and evaluation of a behavioural intervention to reduce vaginal infections (bacterial vaginosis, not an STI) among LBQ women. ${ }^{37}$ The intervention was developed after focus group discussions with LBQ women regarding their sexual practices and risk perceptions to ensure that the intervention was tailored to the target group. $^{38}$ A motivational computer-based selfinterview informed by the health belief model was implemented to address perceived susceptibility, severity, benefits of prevention and perceived barriers to implementing preventative practices; the intervention was associated with increased glove use during sex. ${ }^{37}$ No studies were found that evaluated behavioural interventions on STI prevention generally, including addressing STI knowledge, STI testing and a range of safer sex practices among $\mathrm{LBQ}$ women.

Interventions with MSM have shown some efficacy in reducing risk behaviours. Johnson et al $\mathrm{s}^{36}$ systematic review found that interventions 1 month in duration or less were more effective than longer interventions, and recommended individual skill building and behavioural selfmanagement. Herbst $e t a l^{39}$ reported efficacious interventions involved interpersonal skills training, several delivery methods and involved at least three sessions. Wilton $e t a l^{4}$ study of Many Men, Many Voices (3MV), a six-session group intervention focusing on behavioural and socialstructural determinants of HIV/STI vulnerability and protective behaviours for Black MSM in the USA, reported reduced unprotected anal intercourse among participants postintervention. 3MV applies a unique weekend retreat method to reduce attrition. Herrick et $a l^{40}$ described resilience as an 'untapped resource' in behavioural interventions with MSM. Taken together, evidence highlights the complexity of designing behavioural interventions for HIV/STI risk reduction among MSM.

There remain questions regarding what components would be included in interventions to effectively reduce STI vulnerability among diverse LBQ women. Enhanced understanding of protective strategies-such as adaptive coping strategies and social support-can inform STI prevention strategies. Examining these protective strategies LBQ women employ to resist stigma and promote health is also integral to challenging a disempowering 'passive victim' narrative. ${ }^{41-43}$ Mayer et at $t^{44}$ called for researchers to explore how LGBQ persons: "lead resilient and productive lives in the face of discrimination to develop assets-based interventions that build on community support' (p.30). Adaptive coping styles were associated with reduced HIV/STI risk behaviour among women in the $\mathrm{USA}^{45}$ and young women in Spain, ${ }^{46}$ highlighting the importance of exploring these strategies among sexually diverse women. 
Working in collaboration with community-based agencies in Toronto and Calgary, we will develop and implement Queer Women Conversations (QWC), a group-based psychoeducational HIV and STI prevention intervention for $\mathrm{LBQ}$ women and other women who have sex with women (WSW). This study is informed by conceptualisations of intersectional stigma, referring to the convergence of multiple identity characteristics such as gender, sexual orientation, race and ethnicity, that contribute to both marginalisation (eg, stigma) and opportunity (eg, social support). ${ }^{13}$ This study also draws from the Modified Social Ecological Model (MSEM) framework $^{47}$ to explore intrapersonal (self-esteem, STI knowledge, resilient coping, depression, internalised stigma), interpersonal (safer sex self-efficacy), community (social provisions, community connectedness) and structural (sexual stigma, access to healthcare) factors that may be associated with HIV and STI vulnerability. The lack of attention to efficacious HIV/STI prevention strategies among $\mathrm{LBQ}$ women provides a strong rationale for pilot testing this intervention. We aim to assess feasibility, resources, management issues and scientific impacts from pilot testing the intervention.

\section{STUDY PURPOSE}

The main purpose of this study was to evaluate whether, in comparison with preintervention, LBQ women who attend the QWC group-based HIV/STI prevention intervention in Toronto and Calgary will demonstrate increased safer sex practices. The secondary objective was to assess if, compared to preintervention, participants who receive the QWC intervention will report the following changes in scores postintervention: (1) increased selfesteem, (2) increased resilient coping, (3) increased STI knowledge, (4) reduced depression, (5) increased safer sex self-efficacy, (6) increased social provisions, (7) increased LGBQ community connectedness, (8) reduced sexual stigma and (9) increased access to healthcare.

\section{TRIAL DESIGN AND METHODS \\ Design}

This is a multicentre, non-randomised pragmatic cohort pilot study using a pretest/post-test design with a 6-week follow-up. Purposive venue-based sampling will be used to recruit participants from community-based organisations in Toronto and Calgary.

\section{Randomisation, allocation and blinding}

Randomisation, allocation and blinding are not relevant due to the pilot design.

\section{PARTICIPANTS}

Research participants include self-identified LBQ and other WSW living in Toronto or Calgary. We aim to recruit a total sample of $40 \quad(\mathrm{n}=20$ for each site). Inclusion criteria are self-identified women aged 18 and over; women who identify as LBQ WSW or same-sex attracted; able to provide consent and interested in attending a weekend retreat and completing three surveys. Exclusion criteria include: below 18 years old; does not self-identify as a woman; does not self-identify as LBQ WSW or same-sex attracted; does not have the interest/ability to attend a weekend retreat and three surveys.

\section{SAMPLE SIZE DETERMINATION}

Sample size calculations were guided by the primary and secondary hypotheses and calculated using $G^{*}$ Power V.3.1. For matched pair $\mathrm{t}$ test, effect size: 0.50 , power: 0.90 , critical t: 1.68 , the sample size required is 36 . For this study the prespecified index of significant change is an effect size of 0.50 . We will oversample $(n=44)$ to account for attrition.

\section{RECRUITMENT}

We will engage with a graduate research assistant in Calgary, a research coordinator in Toronto and peer research assistants in each location; peer research assistants in each location will be women who identify as LBQ and are engaged in LBQ community events. Research assistants will be asked to assist with recruitment and will engage local community agencies serving LBQ women and WSW, LBQ events (eg, listserves for LBQ events and parties) and sexual health centres to facilitate accessing a diverse range of $L B Q$ women.

\section{INTERVENTION}

The study has five distinct components: (1) key informant interviews to inform the development of the intervention training manual and survey, (2) pretest, (3) intervention (6 group sessions during a weekend retreat), (4) post-test directly following intervention and (5) follow-up post-test at 6 weeks.

\section{Key informant interviews}

We will hold six key informant interviews (45-60 min in duration) in Toronto to inform the development of the training manual for the intervention for its cultural, gender and contextual relevance for lesbian, bisexual and queer women. We will conduct key informant interviews with experts in LBQ/WSW sexual health and in HIV/STI prevention. The training manual, surveys and the intervention will be modified based on key informant feedback.

\section{Pretest and post-test evaluations}

In order to reduce bias in self-report measures of sexual risk behaviour ${ }^{48}$ we will conduct pretest/post-test and 6-week follow-up surveys using an online self-administered survey. Participants will be provided with an identification number and no identifying information will be collected on the survey. Computer-assisted surveys enhance the reliability and validity of self-reported sexual risk behaviour 
data in HIV research ${ }^{49}$ and have been used similar to the $3 \mathrm{MV}$ approach. ${ }^{24}$ Surveys will include an online informed consent form.

\section{Group-based programme}

The intervention will develop a group-level intervention to address individual and social determinants of HIV/ STI risk and vulnerability. This intervention involves six consecutive $2-3 \mathrm{~h}$ sessions conducted at a weekend retreat; the design was informed by the $3 \mathrm{MV}$ structure. ${ }^{24}$ We will have one retreat in Calgary and one retreat in Toronto; each retreat will include 20 persons. Sessions will be facilitated by the research coordinator and community facilitators who identify as LBQ women and are involved in agencies that serve LBQ women and WSW. The interventions will be conducted in community organisations in each location and will be delivered by the principal investigator and community-based facilitators located at sexual health clinics and LBQ community groups; all community-based facilitators will have expertise in LBQ women's sexual health and wellbeing. Content will be delivered using a variety of techniques including small and large group discussions, role play and arts-based methods. Participants will receive an honorarium of $\$ \mathrm{C} 100$ for attending the weekend retreat and conducting pre/post and 6-week follow-up surveys.

The content areas for each $2 \mathrm{~h}$ session include:

1. Who are we?: Personal goals and objectives from the intervention.

2. Let's Talk about sex 1-sex, bodies, pleasure, safer sex: HIV, STI, safer sex, negotiating safer sex, safer sex self-efficacy.

3. Let's Talk about sex 2-getting the sex that you want!: Sexual stigma, sexuality, barriers and facilitators to safer sex, emotional and mental health, communication and intimacy exercises.

4. Relationships, relationships, relationships: Power relations, healthy relationships, communication skills, intersectional stigma, intimacy.

5. Self-love and self-healing: Internalised stigma, selfesteem, self-acceptance, resilient coping.

6. Building a community of care: Resources and support systems, strategies of building or connecting to communities, barriers and opportunities for self-care and social support.

\section{OUTCOMES}

\section{Primary outcome}

The primary outcome is safer sex practices, measured using the 'Safer Sexual Practices among Lesbian Women' scale. ${ }^{50}$ We will assess two dimensions in this scale: (1) knowledge of safer sex practices and (2) frequency of practicing safer sex strategies.

\section{Secondary outcomes}

Safer sex self-efficacy will be assessed using (1) a modified version of the Condom Use Self-Efficacy Scale ${ }^{51}$ to enhance appropriateness for LBQ women and (2) the Safer Sex Self-Efficacy Scale. ${ }^{52}$ Participants will self-report STI testing history in past 6 weeks. We will measure STI knowledge using the Sexually Transmitted Disease Knowledge Questionnaire (STD-KQ) ${ }^{53}$ We will use the Brief Resilient Coping Scale to assess resilient coping. ${ }^{54}$ Social support will be measured using the Social Provisions Scale. ${ }^{55}$ Connection to LGBQ communities will be assessed using the Community Connectedness Scale. ${ }^{56}$ Enacted and felt-normative sexual stigma will be measured using the Homophobia Scale ${ }^{17}$ and internalised stigma measured using the Short Internalised Homonegativity Scale. ${ }^{57}$ Access to healthcare will be assessed using items from a survey conducted with lesbian women in the USA $^{58}$ Depression will be measured using the Patient Health Questionnaire $2^{59}$ and self-esteem will be measured using the Rosenberg Self-Esteem Scale. ${ }^{60}$

\section{FEASIBILITY CRITERIA}

Feasibility for this pilot study will be assessed using criteria developed by Thabane $e t a l,{ }^{61}$ including: (1) process, such as retention rates for the 2-day retreat, eligibility criteria (sufficient/too restrictive), understanding of survey items, relevance of session content, length of retreat, length of sessions; (2) resources, including length of survey completion, collaboration with community-based agencies and facilitators, assessing information and resources to strengthen the programme; (3) management, such as challenges in study management, data collection, participant follow-up for data collection; (4) changes in primary or secondary outcome variables after participating in the retreat, and the estimated treatment effect.

\section{STATISTICAL METHODS}

Descriptive analyses of sociodemographic (eg, age, income) variables, including means and $\mathrm{SD}$, will be conducted to provide an overview of participant characteristics. Second, items for each scale will be summed to calculate scores for each variable (eg, STI knowledge). Descriptive statistics will be calculated to determine frequencies, means and SD for each summed score. Baseline descriptive statistics will be calculated to summarise sociodemographic variables and other primary/ secondary variables among participants in each location. Differences between locations will be assessed using Student $\mathrm{t}$ tests for continuous variables and $\chi^{2}$ analyses for categorical variables. We will use paired-sample $t$ tests to assess preintervention and post intervention differences in the primary (safer sex practices) and secondary (self-esteem, STI knowledge, resilient coping, depression, internalised stigma, safer sex self-efficacy, social provisions, community connectedness, sexual stigma, access to healthcare) variables directly following the intervention and 3 months postintervention. Statistical analysis will be conducted using SPSS V.10. 


\section{DISCUSSION}

Despite the demonstrated need, there has been inadequate attention given to implementing and evaluating interventions to address HIV/STI risk among LBQ women. This pilot study will allow the research team to refine and improve the survey tools, evaluate the efficacy of the group intervention for impacting target outcomes, and assess the feasibility of this intervention on a larger scale. We will use these findings to inform and refine the development of a larger scale study, with the ultimate goal of improving the health and well-being of LBQ and WSW communities.

\section{ETHICAL CONSIDERATIONS AND DISSEMINATION}

This psychoeducational intervention poses minimal risks to participants. Psychological or emotional risks include that participants may feel uncomfortable, anxious or upset discussing HIV, STI, sexual risk factors, sexual stigma and safer sex. These risks will be mitigated by clearly articulating the free and informed consent process, allowing participants to skip questions, ensuring that participants know that they can withdraw at any time, providing participants with available support resources and with facts about HIV and STI and safer sex for LBQ women. Social risks include loss of privacy and breaches of confidentiality regarding self-disclosed personal information in the Internet-based survey, so no participant names or identifying information will be collected, and the survey will be transferred off of the Internet and onto a secure, password-protected computer belonging to the principal investigator (CHL) as soon as the data collection finishes.

Another social risk is that the facilitator of the focus group and retreat discussions cannot assure that all discussion members will keep all information provided in the discussion confidential or that discussion members may know one another. In order to minimise these risks, participants may skip any discussion questions, if they feel uncomfortable or if they do not wish to answer or participate, and the cofacilitator will be the PI who is welltrained in research ethics and interviewing techniques. Facilitators will stress to other discussion participants the importance of keeping everything said during the discussion confidential, but will additionally indicate that confidentiality cannot be assured and that participants should refrain from saying anything that they would not be comfortable having repeated outside the discussion.

To enhance confidentiality no names or identifying information will be collected on surveys or informed consent forms; and surveys/informed consent forms and surveys will be kept at a locked filing cabinet at the University of Toronto. This study is registered at http:/ / clinicaltrials.gov, registration number NCT02067845.

\section{PUBLICATION POLICY}

The results of the trial will be published according to the Transparent Reporting of Evaluations with Non- randomised Designs (TREND) statement. Regardless of the outcomes, trial results will be published in a peerreviewed scientific journal.

\section{PROJECTED TIMETABLE FOR TRIAL}

Months 1-3: intervention development and ethics submission (October-December 2013)

Months 4-6: recruitment, focus groups and intervention implementation (January-March 2014)

Months 7-9: follow-up data collection (April-June 2014)

Months 10-11: data analysis (July-August 2014)

Months 11-12: report writing, submission of articles for publication and dissemination of results (SeptemberDecember 2014)

Author affiliations

${ }^{1}$ Factor-Inwentash Faculty of Social Work, University of Toronto, Toronto, Canada

${ }^{2}$ Women's College Research Institute, Women's College Hospital, Toronto, Canada

${ }^{3}$ Faculty of Arts, University of Calgary, Calgary, Canada

${ }^{4}$ Women's Health in Women's Hands Community Health Centre, Toronto, Canada

${ }^{5}$ Faculty of Social Work, University of Calgary, Calgary, Canada

Acknowledgements The authors acknowledge the Sharp Foundation, Calgary Sexual Health Centre and Calgary Outlink in Calgary and Women's Health in Women's Hands Community Health Centre, AIDS Committee of Toronto, Griffin Centre ReachOut Program, Sherbourne Health Centre Supporting our Youth (SOY) Program, Women's College Research Institute, Black Coalition for AIDS Prevention, and Planned Parenthood of Toronto; the peer recruiters and facilitators and participants. The authors would like to thank David Lewis-Peart for his valuable contributions.

Contributors $\mathrm{CHL}$ is the principal investigator; WT, DE and MRL are coinvestigators. $\mathrm{CHL}$ and M-JR conceived the idea for the study. CHL led writing the manuscript, DN contributed substantially to the writing of the manuscript. CHL, DN, M-JR, WT, DE and MRL contributed to the study design and methods. All authors reviewed the protocol.

Funding This trial is funded by the Canadian Institutes for Health Research (CIHR) Social Research Centre in HIV Prevention (Fund: 487453).

Competing interests None.

Ethics approval Research ethics approval was attained from the Office of Research Ethics (REB: 29291), University of Toronto, Toronto, Ontario, Canada.

Provenance and peer review Not commissioned; peer reviewed for ethical and funding approval prior to submission.

Data sharing statement The results of the trial will be published according to the Transparent Reporting of Evaluations with Non-randomised Designs (TREND) statement for non-randomised studies. The study data will be shared on clinicaltrials.gov.

Open Access This is an Open Access article distributed in accordance with the Creative Commons Attribution Non Commercial (CC BY-NC 4.0) license, which permits others to distribute, remix, adapt, build upon this work noncommercially, and license their derivative works on different terms, provided the original work is properly cited and the use is non-commercial. See: http:// creativecommons.org/licenses/by-nc/4.0/

\section{REFERENCES}

1. Bauer GR, Welles SL. Beyond assumptions of negligible risk: sexually transmitted diseases and women who have sex with women. Am J Public Health 2001;91:1282-6. 
2. Logie $\mathrm{CH}$, Gibson MF. A mark that is no mark? Queer women and violence in HIV discourse. Cult Health Sex 2013;15:29-43.

3. Marrazzo JM. Sexually transmitted infections in women who have sex with women: who cares? Sex Transm Infect 2000;76:330-2.

4. Marrazo JM, Gorgos LM. Emerging sexual health issues among women who have sex with women. Curr Infect Dis Rep 2012:14:204-11.

5. Peel E, Thomson M. Editorial introduction: lesbian, gay, bisexual, trans and queer health psychology: historical development and future possibilities. Fem Psychol 2009;19:427-36.

6. Pinto VM, Tancredi MV, Neto A, et al. Sexually transmitted disease/ HIV risk behaviour among women who have sex with women. AIDS 2005;19:S64-9

7. Fethers $\mathrm{K}$, Marks $\mathrm{C}$, Mindel A, et al. Sexually transmitted infections and risk behaviours in women who have sex with women. Sex Transm Infect 2000;76:345-9.

8. Steele LS, Ross LE, Dobinson C, et al. Women's Sexual Orientation and Health: results from a Canadian Population-Based Survey Women Health 2009;5:353-67.

9. Logie C, Rwigema MJ. Associations between sexual stigma and safer sex practices among lesbian, bisexual and queer women in Toronto, Canada. Poster presentation for XIX International AIDS Conference 2012, July, Washington, DC.

10. Bevier PJ, Chiasson MA, Heffernan RT, et al. Women at a sexually transmitted disease clinic who reported same-sex contact: their HIV seroprevalence and risk behaviors. Am J Public Health 1995;10:1366-71.

11. Goodenow C, Szalacha LA, Robin LE, et al. Dimensions of sexual orientation and HIV-related risk among adolescent females: evidence from a statewide survey. Am J Public Health 2008;6:1051-8.

12. Logie C, James L, Tharao W, et al. 'We don't exist': a qualitative study of marginalization experienced by HIV-positive lesbian, bisexual, queer and transgender women in Toronto, Canada. J Int AIDS Soc 2012;15:17392.

13. Logie C, James L, Tharao W, et al. Race, gender, sexual orientation, HIV and sex work: intersectional stigma experienced by women living with HIV in Ontario, Canada. PLoS Med 2011;11: e1001124.

14. Herek GM. Beyond "homophobia": thinking about sexual prejudice and stigma in the twenty-first century. Sex Res Soc Policy 2004:1:6-24.

15. Alvy LM, McKirnan DJ, Mansergh G, et al. Depression is associated with sexual risk among men who have sex with men, but is mediated by cognitive escape and self-efficacy. AIDS Behav 2010;15:1171-9.

16. Yi H, Sandfort TGM, Shidlo A. Effects of disengagement coping with HIV risk on unprotected sex among HIV-negative gay men in New York City. Health Psychol 2010;2:205-14.

17. Diaz RM, Ayala G, Bein E, et al. The impact of homophobia poverty and racism on the mental health of gay and bisexual Latino men: findings from 3 US cities. Am J Public Health 2001:91:927-32.

18. Tjepkema M. Health care use among gay, lesbian and bisexual Canadians. Health Rep 2008;19:52-64.

19. Charnley $\mathrm{H}$, Langley J. Developing cultural competence as a framework for antiheterosexist social work practice. J Soc Work 2007:7:307-21.

20. Pugh S. Assessing the cultural needs of older lesbians and gay men: implications for practice. Practice 2005;17:207-18.

21. Fish J. Far from mundane: theorising heterosexism for social work education. Soc Work Educ 2008;27:182-93.

22. McNair RP, Anderson S, Mitchell A. Addressing health inequalities in Victorian lesbian, gay, bisexual and transgender communities. Health Promot $J$ Austr 2001;11:305-11.

23. Manthorpe J. Nearest and dearest? The neglect of lesbians in caring relationships. Br J Soc Work 2003;33:753-68.

24. Wilton T, Herbst JH, Coury-Doniger P, et al. Efficacy of an HIV/ST prevention intervention for black men who have sex with men: findings from the Many Men, Many Voices (3MV) project. AIDS Behav 2009;13:532-44.

25. Bayliss K. Social work values, anti-discriminatory practice and working with older lesbian service users. Soc Work Educ 2000;19:45-53.

26. Donovan $\mathrm{C}$, Hester M, Holmes J, et al. Comparing domestic abuse in same sex and heterosexual relationships. Swindon: ESRC award no. RES-000-23-0650, 2006

27. Hardman KLJ. Social workers' attitudes to lesbian clients. Br J Soc Work 1997:27:545-63.

28. Hunt R, Fish J. Prescription for change: lesbian and bisexual women's health check. London: Stonewall, 2008. http://www. stonewall.org.uk/documents/prescription_for_change_1.pdf. [accessed 29 Nov 2012].
29. Sale A. Back in the closet: confronting the needs of ageing gay and lesbian people. Community Care 2002;1424:30-1.

30. Spectrum. Count me in: health and social care needs assessment of LGBT communities in Brighton and Hove 2003. http://www. spectrum-lgbt.org/countmein/summary.htm [accessed 28 Nov 2012].

31. Davis TS, Saltzburg S, Locke CR. Supporting the emotional and psychological well being of sexual minority youth: youth ideas for action. Child Youth Serv Rev 2009;31:1030-41.

32. Fish J. Invisible no more? Including lesbian, gay and bisexual people in social work and social care. Practice 2009;21:47-64

33. Davies M, Addis S, MacBride-Stewart S, et al. The health, social care and housing needs of lesbian, gay, bisexual and transgender older people: literature review. Cardiff University, Centre for Health Sciences Research, 2006.

34. Greaves B, Fish J, Graham D, et al. The health and social care needs of lesbian, gay and bisexual people in Leicester. Unpublished report submitted to the Leicester Public Health Partnership, 2007

35. Caceres CF. HIV among gay and other men who have sex with men in Latin America and the Caribbean: a hidden epidemic? AIDS 2002;16:S23-33.

36. Johnson WD, Diaz RM, Flanders WD, et al. Behavioral interventions to reduce risk for sexual transmission of HIV among men who have sex with men. Cochrane Database Syst Rev 2008;3:CD001230. (accessed 2 Dec 2012)

37. Marrazzo J, Thomas KK, Ringwood K. A behavioral intervention to reduce persistence of bacterial vaginosis among women who report sex with women: results of a randomized trial. Sex Transm Infect 2011;87:399-405

38. Marrazzo JM, Coffey P, Bingham A. Sexual practices, risk perception and knowledge of sexually transmitted disease risk among lesbian and bisexual women. Perspect Sex Reprod Health 2005;37:6-12.

39. Herbst $\mathrm{JH}$, Beeker $\mathrm{C}$, Matthew $\mathrm{A}$, et al. The effectiveness of individual, group and community-level HIV behavioral risk-reduction interventions for adult men who have sex with men: a systematic review. Am J Prev Med 2007;32:S38-67.

40. Herrick AL, Lim SH, Wei C, et al. Resilience as an untapped resource in behavioural intervention design for gay men. AIDS Behav 2011;15:S25-9.

41. Campbell $\mathrm{C}$, Deacon $\mathrm{H}$. Unravelling the contexts of stigma: from internalization to resistance to change. J Community Appl Soc 2006;16:411-17.

42. Link BG, Phelan JC. Conceptualizing stigma. Annu Rev Sociol 2001;27:363-85.

43. Meyer $\mathrm{IH}$. Minority stress and mental health in gay men. $J$ Health Soc Behav 1995;36:38-56.

44. Mayer KH, Bekker LG, Grulich A, et al. Comprehensive clinical care for men who have sex with men: an integrated approach. Lancet 2012;12:40-51.

45. Nyamathi A, Stein JA. Assessing the impact of HIV risk reduction counseling in impoverished African American women: a structural equations approach. AIDS Educ Prev 1997;9:253-73.

46. Teva I, Bermudez MP, Buela-Casal G. Sexual sensation seeking social stress, and coping styles as predictors of HIV/STD risk behaviors in adolescents. Youth Soc 2010;42:255-77.

47. Baral S, Logie $\mathrm{CH}$, Grosso A, et al. Modified social ecological model: a tool to guide the assessment of the risks and risk contexts of HIV epidemics. BMC Public Health 2013;13:482.

48. Hayes R, Kapiga S, Padian N, et al. HIV prevention research: taking stock and the way forward. AIDS 2010;24:S81-92.

49. Rogers SM, Willis G, Al-Tayyib A, et al. Audio computer assisted interviewing to measure HIV risk behaviours in a clinic population. Sex Transm Infect 2005;81:501-7.

50. Fishman SJ, Anderson EH. Perception of HIV and safer sexual behaviors among lesbians. J Assoc Nurses AIDS Care 2003;14:48-55

51. Kalichman SC, Rompa D, DiFonzo K, et al. Initial development of scales to assess self-efficacy for disclosing HIV status and negotiating safer sex in HIV-positive persons. AIDS Behav 2001;5:291-6.

52. Redding CA, Rossi JS. Testing a model of situational self-efficacy for safer sex among college students: stage and gender-based differences. Psychol Health 1999;14:467-86.

53. Jaworski BC, Carey MP. Development and psychometric evaluation of a self-administered questionnaire to measure knowledge of sexually transmitted diseases. AIDS Behav 2007;11:557-74.

54. Sinclair VG, Wallston KA. The development and psychometric evaluation of the Brief Resilient Coping Scale. Assessment 2004;11:94-101. 
55. Russell DW, Cutrona CE. Social provisions scale. lowa State University, 1984.

56. Frost DM, Meyer IH. Measuring community connectedness among diverse sexual minority populations. J Sex Res 2012;49:36-49.

57. Currie MR, Cunningham EG, Findlay BM. The Short Internalized Homonegativity Scale: examination of the factorial structure of a new measure of internalized homophobia. Educ Psychol Meas 2004;64:1053-67.
58. Diamant AL, Schuster MA, Lever J. Receipt of preventive health care services by lesbians. Am J Prev Med 2000;19:141-8.

59. Kroenke K, Spitzer RL, Williams JB. The Patient Health

Questionnaire-2: validity of a two-item depression screener. Med Care 2003;41:1284-92.

60. Rosenberg M. Society and the adolescent self-image. Princeton, $\mathrm{NJ}$ : Princeton University Press, 1965.

61. Thabane L, Ma J, Chu R. et al. A tutorial on pilot studies: the what, why and how. BMC Med Res Methodol 2010;10:1. 